\title{
1986 Von Hippel Award Honors Minko Balkanski
}

The Materials Research Society has named Minko Balkanski the recipient of its 1986 Von Hippel Award. Balkanski, professor of physics and director of the Solid State Physics Laboratory at the Universite Pierre et Marie Curie, Paris, will receive the Society's highest honor December 3, at 6:00 p.m., during the 1986 Fall Meeting in Boston. The award consists of a cash honorarium and commemorative plaque.

The award cites Dr. Balkanski for "his seminal contributions to the spectroscopies of semiconducting and other materials with consequent understanding of bulk and surface structure and excitations,... his extensive contributions to interdisciplinary, international materials research collaborations, and...his extraordinarily productive investment in the education and training of materials scientists."

Balkanski's research and professional activities have had a worldwide impact on materials science. He pioneered many important areas and made significant contributions to many others. He spent three years as a research fellow at the Massachusetts Institute of Technology MIT in Prof. Arthur von Hippel's laboratory, where he was introduced to the concept of interdisciplinary materials research. Upon his return to France, he built laboratories at Ecole Normale Superieure and later at the Université Pierre et Marie Curie that are recognized as being among the world's best in materials science. At the latter, he maintained the thrust in basic research of lat tice dynamics and spectroscopy while at the same time broadening the program to include studies on amorphous silicon, optical electronics, and atomic motion in solids.

His laboratory has attracted researchers from a round the world and a number of his students are now leaders in their fields. responsible for a large fraction of the science being done in semiconductors and optics in France.

His lab has helped not only French physics, but also American, British, German and Chinese physics, both scientifically as well as in overcoming a natural insularity which tends to develop in each country. This kind of international mixing is extremely important to the development of physics and Balkanski's contributions to it have been crucial.

It may be appropriate to characterize Balkanski's research by saying that he explored the coupling of photons to elementary excitations in solids. In the late 1950s, he suggested that exciton diffusion was a major mechanism for energy transport, and he participated in the invention of the polariton (he was working with von Hippel and John Slater at the time). Next he

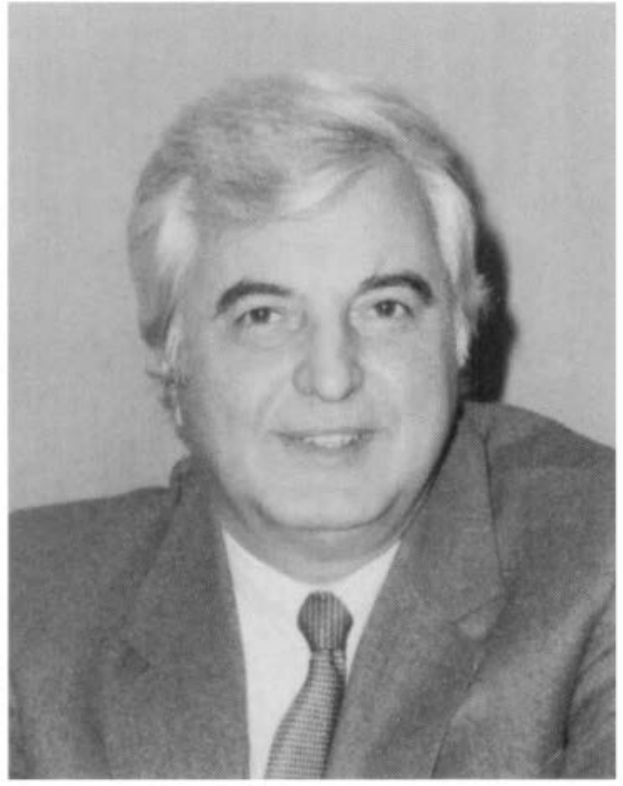

Balkanski arranged to have a variety of scientists working in many fields bring their special theoretical and experimental talents to bear on the research projects. He created a productive at mosphere and used his exceptional instinct for choosing active areas to inspire students and senior scientists. He also never lost track of the importance of writing reviews and books to enable new researchers to participate in areas he felt were exciting. Realizing the importance of international conferences for exchanging information, he and associates working under his direction are credited with establishing the style and organization of some of the most successful series of conferences in physics.

Balkanski has served as a scientific consultant both in France and the United States and has served professional organizations in numerous capacities. In addition to his current teaching responsibilities at Université Pierre et Marie Curie, he is also dean of international affairs at the University, scientific advisor for Thomson C.S.F. and for the director of E.S.I.E.E. He is a member of the Publications Board of the European Physical Society and a member of the editorial boards of seven scientific journals. He is the author or editor of nine books and well over 500 scientific articles.

mode, and significant contribution the areas of impurity-induced density of states spectra, lattice dynamics of semiconductor alloys, superlattice phenomena, and phonon modes in ferroelectrics. He is one of the pioneers in the area of Raman scattering in semiconductors.

Electron-phonon coupling is another area where Balkanski's influence has been felt. His early work on continuum-discrete phonon interference and distortion of line shapes led him to a significant effort in an area which may be referred to as manybody aspects of solid-state spectroscopy.

Balkanski and his students have had a major influence on surface physics. Photoemission studies in his laboratory on semiconductor surfaces with adsorbates are at this time the world's best.

During the 1960s and 1970s, he and his group provided some of the best data available to unravel the origins of the structure in optical and electronic materials. He also provided some of the most important data on narrow gap semiconductors.

More recent research has focused on amorphous silicon, glass-crystalline transformations, optoelectronics, and superionic conductors. Again, Balkanski has picked the most relevant experiments to do, and he has formed important collaborations with theorists and experimentalists to solve major problems.

Following in the von Hippel tradition,

\section{Previous} Von Hippel Winners

The Von Hippel Award bears the name of its first recipient, Arthur Robert von Hippel, whose pioneering research and unfettered spirit inspired the prize. Emer-i itus professor of the Massachusetts Institute of Technology, von Hippel's research in dielectrics, semiconductors, ferromagnetics and ferroelectrics resulted in the publication of two visionary books. Molecular Science and Molecular Engineering and Molecular Designing of Materials and Devices.

Von Hippel studied electrophysics at the University of Goettingen, which granted him a PhD in 1924. After a decade of teaching and research in Europe he joined the MIT faculty in 1936. It was in his lab that the example of scientists working cooperatively to solve the mysteries of materials from the atomic to the microstructural level first challenged the parochialism that had prevailed before and demonstrated the utility of the interdisciplinary approach which the Materials Research Society fosters and embodies.

Continued 
The second recipient of the prize, in 1978 , was W. O. Baker, president of Bell Telephone Laboratories. Baker joined Bell Labs in 1939, having received his $\mathrm{PhD}$ in physical chemistry from Princeton the previous year. First as member of the technical staff and subsequently in various leadership positions, he studied solid state materials and macromolecules, dielectric and dynamic mechanical properties of crystals and glasses, information processing technology, and plastics, fibers, and natural and synthetic rubbers.

In addition to research, Baker has devoted himself to numerous civic, governmental, and scientific committees and commissions. In 1957 Washington University, where he had done his undergraduate work, awarded him its honorary Doctor of Science degree. At least 17 other institutions of higher education have presented him with similar awards.

David Turnbull, Gordon McKay Professor of Applied Physics at Harvard, was the Von Hippel Award recipient in 1979. A physical chemist by training, Turnbull's research has encompassed a broad range: thermionic emission, thermodynamic properties of gases at high pressures, corrosion in non-aqueous media, diffusion in metals, kinetics of nucleation in solid state transformation, solidification, theory of liquid and glass.

Turnbull received his PhD from the University of Illinois in 1939. He began his career at Case Institute of Technology, then joined the research laboratory of the General Electric Company in 1946, where he remained until he joined the Harvard faculty in 1962.

W. Conyers Herring, 1980 recipient of the prize, is professor of applied physics at Stanford University. He has had a seminal influence on materials science and solid state physics, contributing to the under- standing of solid state surfaces that underpins the field of crystal growth, sintering, and plastic flow at high temperatures. Together with J. K. Galt he realized and demonstrated that whiskers of high crystalline perfection would exhibit extraordinary mechanical properties.

Herring received his $\mathrm{PhD}$ from Princeton in physics in 1937. He taught at MIT, Princeton, and the University of Missouri. and from 1941 to 1945 was a member of the War Research staff at Columbia University. He joined Stanford in 1936 after 30 years at Bell Laboratories.

James W. Mayer, the Society's 1981 honoree, is Francis Norwood Bard Professor of Materials Science and Engineering at Cornell University. Mayer has had a profound influence on the development of modern materials science with particular emphasis on semiconductor materials. Almost every area he has worked in has turned out to be important. For example, his research on implantation identified the damage and epitaxial regrowth phenomena long before the technique was accepted as an integral part of the semiconductorindustry. He has been a pioneer in the use of ion beam techniques for materials analysis.

Mayer received his $\mathrm{PhD}$ in physics from Purdue in 1960. He was with Hughes Aircraft Company until 1967, when he became professor of electrical engineering at Caltech, where he remained until joining Cornell in 1980. Among his other accomplishments at Caltech, he taught scubadiving for a decade.

Clarence M. Zener, emeritus university professor of Carnegie-Mellon University received the Von Hippel Award in 1982. His contributions to the physics of metals and to mathematics are among the most fundamental and original of any 20thcentury scientist. He performed the definitive work on internal friction in solids, and provided the theoretical foundation for a line of research that resulted in the invention of the Zener diode and may be said to underlie the development of semiconductors.

A graduate of Harvard, which granted him his PhD in 1929, Zener accepted a series of academic appointments, interrupted by a 15-year association with Westinghouse Electric Company, during which he built a research institution among the finest in the world. He was appointed university professor at Carnegie-Mellon in 1968.

The Von Hippel Award in 1983 was presented to Sir Peter B. Hirsch, Isaac Wolfson Professor of Metallurgy at the University of Oxford and Chairman of the United Kingdom Atomic Energy Authority. The first person to observe dislocations in transmission of electron microscopy, Sir Peter is the author, with others, of the fundamental text in the field, Electron Microscopy of Thin Crystals. His The Physics of Metals, Vol. II, Defects, is equally important. With his colleagues and students, Sir Peter is largely responsible for the elevation of electron microscopy to its preeminent position in the study of the microstructure of materials.

Sir Peter obtained his PhD at Cambridge in 1951. He pursued an academic career, culminating in his appointment to Oxford in 1966 as head of the Department of Metallurgy and Science of Materials. A Fellow of the Royal Society and a recipient of its Royal Medal, Sir Peter has received scores of prizes and honorary degrees, notably the Rosenhain Medal of the Institute of Metals, and the C. V. Boyes Prize of the Institute of Physics and Physical Society. He was made Knight Bachelor in 1975.

Continued

\section{MRS}

THE VON HIPPEL AWARD

The Von Hippel Award is the Materials Research Society's most prestigious award. It is presented annually to the living scientist who, in the Society's estimation, best exemplifies the originality, brilliance of intellect, and diligence of purpose throughout a career that are the hallmark of science at its best; who adheres to the strictest ethical standards and highest code of professional integrity; and whose vision transcends conventional disciplines, as does the science of materials itself.

The award consists of a synthetic ruby crvstal suitably mounted, a cash honorarium, and a lifetime membership in the Society. It is named for Arthur Robert von Hippel, emeritus professor of Massachusetis Institute of Technologv, who was also its first recipient.

The MRS Awards Commillee solicils nominations annually from among the membership and elsewhere in the community of materials scientists. The nominees are evaluated against the Society's criteria, rather than against each other. From among the candidates it has reviewed, the Awards Committee puts forward the names of the principal contenders for the honor: The nominees are considered in confidence by the Council of the Society. The Council, representative of the many disciplines and institutions within MRS, makes the final decision by a majority vote. 
Walter L. Brown, head of the Radiation Physics Department, AT\&T Bell Laboratories, was the 1984 Von Hippel Award recipient. He has demonstrated an extensive record of achievement in the field of semiconductor science and technology and leadership in university-industry collaboration. His early experiments with Brattain, Schockley, and Fletcher laid the foundation of understanding of surface states and inversion layers in silicon and germanium and made possible the developments of MOSFET technology. His interest in semiconductors led to the design of solid state radiation detectors that were flown in the first Telstar experimental communications satellite and were used to determine the nature of the particles that are trapped in the Van Allen belts

His interest in particle detectors and high energy particle damage led to his involvement in the organization of the RutgersBell Labs Accelerator Program which has served as a model for industry-university collaboration. Brown nurtured an early research program on particle channeling that proved to be an important adjunct to the development of ion implantation doping of semiconductors. His research in sputtering similarly led to significant contributions to application in chemical analysis.

Brown received his $\mathrm{PhD}$ from Harvard University, and began his career with Bell Laboratories in 1950.

John W. Cahn, the 1985 Von Hippel recipient, is a senior fellow at the Center of Materials Science, National Bureau of Standards. He joined the NBS staff in 1978 after 14 years as professor of materials science at Massachusetts Institute of Technology. Cahn's contributions have affected every area of materials science and have strongly influenced statistical physics as well. His initial interest in interfaces and their role in phase transformations began in 1954, when he joined the Hollomon Metallurgy and Ceramics group of the G.E. Research Laboratory as a member of the Chemical Metallurgy section headed by David Turnbull. Cahn derived the conditions under which solid-state transformation kinetics should be dominated by nucleation at the boundaries, edges, or corners of grains. He also developed the quantitative theory for preferential nucleation of incoherent phases on dislocations. The Cahn-Hilliard equation for the free energy of non-uniform systems is often the starting point of statistical physical treatments of a variety of interfacial phenomena, and Cahn's theory for the coherent spinodal has illuminated the understanding of the dependence of magnetic and mechanical properties on interphase morphology and has provided valuable guidance for alloy design. Cahn's most recent contribution has been his involvement, with D. Schectman and others, in the discovery of quasicrystalline phases.

\section{MRS}

\section{Graduate Student Awards Announced for 1986 MRS Fall Meeting}

The Materials Research Society Awards Committee has selected 14 recipients of Graduate Student Awards to be presented at the 1986 Fall Meeting in Boston. The students receive a commemorative plaque, a waived meeting registration fee, and a cash prize. They will be recognized at the Awards Ceremony on Wednesday, December 3,1986 at 6:00 p.m. in the Grand Ballroom of the Boston Marriott/Copley Place Hotel.

Students were judged on the originality, cogency, quality, and impact of their work in a field related to one of the symposia at the 1986 Fall Meeting. The students were also judged on the independence they displayed in their research and on their promise for future accomplishments in materials research.

In selecting recipients, the Awards Committee relies on the application material submitted by the student, on the evaluation of that material by the relevant symposium chairs, and on a supporting letter from the student's faculty advisor. Many more deserving candidates applied this year than could receive the limited number of awards available. According to Awards Committee Chairman, Elton N. Kaufmann (Lawrence Livermore National Laboratory), "Congratulations a re really due to all the applicants-their work is quite impressive. It would be nice if we could find awards for all of these excellent students."

The following students will receive awards:

Lisa Parechanian Allen, Materials Science and Engineering, University of California at Berkeley, "Surface Faceting of (110) GaAs: Analysis and Elimination" (Symposium I)

Harry A. Atwater, Electrical Engineering and Computer Science, Massachusetts Institute of Technology, "Ion Beam Enhanced Grain Growth in Thin Films" (Symposium A)

Robert N. Bicknell, Physics, North Carolina State University, "Controlled Substitutional Doping of CdTe Films" (Symposia Q and R)

Yang-Tse Cheng, Applied Physics, California Institute of Technology, "Studies of a Phenomenological Model of Ion Mixing in Metals" (Symposium A)

Charles Michael Greenlief, Chemistry, University of Texas at Austin, "Potassium Adsorption on $\mathrm{Pt}(111)$ and Its Effect on CO Chemisorption" (Symposium J)

Harald Heinecke, Electrical Engineering, Technical University Aachen, "Plasma Stimulated Growth of InP from TEl and $\mathrm{PH}_{3}{ }^{\prime \prime}$ (Symposium B)

Karen Holloway, Materials Science and Engineering, Stanford University, "Interfacial Reactions in Titanium-Silicon Multilayers" (Symposium D)

Andre Yan-Jyh Lee, Materials Science, University of Illinois at Urbana-Champaign, "Matrix Effect on the Relaxation of Uniaxially Strained Linear Polymer Melts" (Symposium F)

Matthew R. Libera, Materials Science and Engineering, Massachusetts Institute of Technology, "Metal Nucleation in Atomized Droplets Catalyzed by SphericallyShaped Substrate Particles" (Symposium G)

Kevin P. McAlea, Chemical Engineering, University of Delaware, "Small Angle Neutron Scattering Studies of Polyethylene Terephthalate" (Symposium F)

Paul F. Miceli, Physics, University of Illinois at Urbana-Champaign, "Critical Behavior of Hydrogen in Nb/Ta Superlattices" (Symposium T)

Scott M. Schlorholtz, Civil Engineering, lowa State University, "Variability and Trends in lowa Fly Ashes" (Symposium N)

David William Susnitzky, Materials Science and Engineering, Cornell University, "Surface Morphology of Single Crystal Ceramics" (Symposium I)

Gang Xiao, Physics and Astronomy, The Johns Hopkins University, "Cu/Ni Superlattices with [100] Texture" (Symposium D)

"Temperature Dependence of the Spontaneous Magnetization of the Fe Particles in Fe-SiO $\mathrm{S}_{2}$ Granular Solids" (Symposium V) 